\title{
JURISPRUDENCIA AMBIENTAL EN LA RIOJA \\ (SEGUNDO SEMESTRE 2019)
}

\author{
LUCía MUÑOZ BENITO \\ Contratada predoctoral FPI-CAR 2019 \\ Universidad de La Rioja
}


SUMARIO: 1. Introducción. 2. Impuesto riojano sobre Grandes Establecimientos Comerciales 3. Evaluación de impacto ambiental: ¿fraude de ley? 4. Licencia de obras y ambiental: condición exterior de la terraza de un bar. 5. Sanciones en el ámbito de la caza y pesca.

\section{INTRODUCCIÓN}

En el periodo objeto de recopilación el Tribunal Superior de Justicia de La Rioja ha dictado cinco sentencias en materia medio ambiental de las que se va a dar cuenta en esta crónica.

De estas sentencias, dos tienen que ver con sanciones impuestas en el ámbito de la caza y pesca mientras que las restantes versan sobre el Impuesto sobre Grandes Establecimientos Comerciales, un posible fraude de ley en la realización de la evaluación de impacto ambiental de un proyecto y, por último, sobre la negación del otorgamiento de una licencia de obra y ambiental para la apertura de un bar-restaurante por no cumplir las condiciones exigidas.

\section{IMPUESTO RIOJANO SOBRE GRANDES ESTABLECIMIENTOS COMERCIALES}

La Sentencia del TSJ de La Rioja núm. 152/2019, de 15 de mayo resuelve un recurso contencioso-administrativo presentado por la empresa Decathlon solicitando que se anulara la Resolución del Tribunal Económico-Administrativo de La Rioja que desestimaba la reclamación económico-administrativa presentada por la citada compañía contra la liquidación complementaria provisional por el concepto Impuesto sobre Grandes Establecimientos Comerciales (IGEC).

El citado impuesto1 tenía identidad sustancial, según el TSJ, con el Impuesto de Grandes Establecimientos Comerciales en Cataluña, sobre cuya compatibilidad con el ordenamiento de la Unión Europea ya se había pronunciado el Tribunal

1 Regulado por la Ley 7/2012, de 21 de diciembre, de Medidas Fiscales y Administrativas para el año 2013, gravaba, según su art. 36, "el impacto urbanístico y medioambiental que concurre en determinados establecimientos comerciales (aquellos con más de 2500 m2) como consecuencia de estar implantados como grandes superficies". Con él se pretendía compensar el impacto medioambiental de la actividad de estos establecimientos y los ingresos obtenidos iban destinados a programas de protección del medio ambiente. Este impuesto fue posteriormente suprimido por Ley 6/2015, de 29 de diciembre de 29 de diciembre, de Medidas Fiscales y Administrativas para el año 2016. 
de Justicia de la Unión Europea en Sentencia de 26 de abril de 2018. En el plano nacional, el Tribunal Supremo también se había pronunciado sobre este impuesto en la Sentencia núm. 1424/2018, de 26 septiembre y, por su parte, el Tribunal Constitucional -entre otras, en la STC 122/2012, de 5 de junio y la STC 53/2014, de 10 de abril- ya había afirmado la constitucionalidad de distintas leyes autonómicas que regulaban este tipo de impuestos.

Sendos pronunciamientos le sirvieron en esta ocasión al TSJ de La Rioja para desestimar el recurso.

Así, por un lado, el TJUE había dicho que la normativa comunitaria (arts. 49 y 54 TFUE) no se opone a un impuesto como el controvertido que grava a los grandes establecimientos comerciales y que tampoco constituye una ayuda de Estado (art. 107.1 TFUE) un impuesto que grava a los establecimientos en función de su superficie de venta, ni que exonera o concede una reducción en la base liquidable a ciertos tipos de grandes establecimientos. Sin embargo, la no sujeción a este impuesto de los grandes establecimientos comerciales colectivos sí podía constituir una ayuda de Estado por tener carácter selectivo.

Por su parte, el TS en la Sentencia anteriormente citada y teniendo en cuenta las limitaciones de control que tenía -dado que la recurrente era la Asociación Nacional de Grandes Empresas de Distribución y, en consecuencia, no sujeto pasivo del impuesto- simplemente se limitó a anular el Decreto catalán 342/2001 por el que se aprobaba el Reglamento del IGEC en cuanto recogía la exención del impuesto de los establecimientos comerciales colectivos de superficie superior a $2.500 \mathrm{~m} 2$ por constituir, conforme al TJUE, una ayuda de Estado.

En este sentido, el TSJ de La Rioja afirma que las consideraciones anteriores de ambos tribunales sobre las grandes superficies colectivas afectan a las exenciones incluidas en la normativa, pero "no convierten la liquidación impugnada en el presente procedimiento en contraria al ordenamiento jurídico", añadiendo además que "es coherente con los objetivos perseguidos un criterio basado en la superficie de venta para distinguir entre las empresas según que su impacto ambiental sea más o menos intenso, en consecuencia, la liquidación tributaria recurrida que se emite en aplicación de una legislación que establece el criterio de sujeción al impuesto basado en la superficie de venta, es conforme a derecho". 


\section{EVALUACIÓN DE IMPACTO AMBIENTAL: ¿FRAUDE DE LEY?}

En el recurso que resuelve la Sentencia del TSJ de La Rioja núm. 206/2019, de 27 de junio, se solicitaba la nulidad de la Resolución de la Dirección General de Innovación, Trabajo, Industria y Comercio por la que se autorizaba, se aprobaba el proyecto de ejecución y se declaraba de utilidad pública la instalación "Variante de línea mixta (aérea-subterránea) a 66 kV denominada "Haro Norte"». La recurrente alegaba tres motivos en apoyo de su recurso: la falta de justificación de la utilidad pública, la posibilidad de realizar el proyecto en otro trazado que causaría menos impacto ambiental y el fraude de ley por eludir la evaluación de impacto ambiental ordinaria fraccionando los proyectos.

En este sentido, la Sala entiende, por un lado, que la utilidad pública está plenamente justificada y, por otro lado, da la razón a una de las codemandadas en cuanto a la inviabilidad de realizar el proyecto en el trazado que quería la demandante, que consistía en aprovechar la zona donde ya existía una línea construida para reducir los impactos ambientales por no crear afecciones distintas de las que ya existían.

El tercer y principal argumento de la parte actora tenía que ver, como adelantábamos, con la existencia de fraude de ley. La demandante sostenía que la línea formaba parte de un proyecto que se había fraccionado en proyectos de igual naturaleza y realizados en el mismo espacio físico para evitar rebasar los umbrales que determinaban el sometimiento a evaluación de impacto ambiental ordinaria. En consecuencia, entendía que no se detallaban las afecciones reales al medio ambiente y los informes de las distintas Administraciones Públicas y organismos eran parciales y limitados.

En efecto, del proyecto de ejecución resultaba que se contemplaba la instalación de una línea eléctrica a $66 \mathrm{kV}$ con una longitud aproximada de 3 kilómetros, lo que la encuadraría en el Anexo II, Grupo 4, apartado b) de la Ley 21/2013, de 9 de diciembre, de evaluación de impacto ambiental, "construcción de líneas para la transmisión de energía eléctrica (proyectos no incluidos en el anexo I) con un voltaje igual o superior a $15 \mathrm{kV}$, que tengan una longitud superior a $3 \mathrm{~km}$, salvo que discurran íntegramente en subterráneo por suelo urbanizado, así como sus instalaciones asociadas". Por lo tanto, estaría sometida a evaluación de impacto ambiental simplificada, como así se hizo. 
Sin embargo, en este sentido, la parte actora aportó un informe pericial donde se señalaba que el hecho de que se iniciara la tramitación administrativa de 9 proyectos de infraestructuras eléctricas en la misma zona en un breve lapso de tiempo indicaba que se trataba de un proyecto global y que lo correcto hubiera sido tramitar los proyectos como uno solo, con la consecuente evaluación de impacto ambiental ordinaria por superar los umbrales para la evaluación de impacto ambiental simplificada, ya que solo así se podía obtener una evaluación real de los impactos en el medio ambiente.

Este informe parece ser contrarrestado, en opinión del TSJ, con el informe aportado por la codemandada Iberdrola en el que se afirma que no todos los proyectos los presentó el mismo titular y no todos tenían la misma naturaleza. Por lo que, con base en él, el TSJ desestima el recurso al entender que no se ha omitido el procedimiento de evaluación de impacto ambiental exigido para el proyecto ni se ha actuado, por lo tanto, en fraude de ley.

\section{LICENCIA DE OBRAS Y AMBIENTAL: CONDICIÓN EXTERIOR DE LA TERRAZA DE UN BAR}

EI TSJ de la Rioja en la Sentencia núm. 175/2019, de 30 de mayo resuelve en apelación un recurso sobre la Sentencia núm. 327/2018, de 27 de diciembre dictada por el Juzgado de lo Contencioso-Administrativo de Logroño que desestimaba el recurso contencioso-administrativo presentado contra dos resoluciones administrativas denegatorias de la licencia ambiental y de obras para la ampliación de bar a bar-restaurante junto con la legalización de terraza en zona libre privada.

Ambas resoluciones denegaban la licencia solicitada por la recurrente por entender que la zona libre privada con la que contaba el bar y en la que se pretendía instalar una terraza, no tenía la condición de exterior y, en consecuencia, su instalación contravenía lo dispuesto en las Normas Urbanísticas del Plan General Municipal de Logroño.

Entendía la recurrente que la concesión de licencias urbanísticas es una actuación de carácter reglado donde no cabe ninguna decisión discrecional, sin embargo, el TSJ advierte que no va en contra del ordenamiento jurídico la 
exigencia de requisitos -como había solicitado en reiteradas ocasiones el Inspector Técnico para conceder la licencia- que aseguren que la actividad se realizaría en su totalidad en el local interior y la zona libre privada quedaría inutilizable.

Por otro lado, en cuanto a la legalización de la terraza en la zona libre privada, concluye el TSJ que el concepto exterior al que se refieren las Normas Urbanísticas del Plan General Municipal de Logroño es aquel espacio que se desarrolla en continuidad a partir de su contacto con el espacio público, sin que valga el contacto visual -como pretendía la recurrente- para entender cumplida la característica de "exterior". Solo así se preserva a otros moradores de los edificios de la contaminación acústica y garantiza en mayor medida su intimidad.

Por todo lo anterior, el TSJ entiende que es ajustada a derecho la decisión de denegar la legalización de la actividad desarrollada en la terraza y desestima el recurso de apelación.

\section{SANCIONES EN EL ÁMBITO DE LA CAZA Y PESCA}

Como viene siendo habitual, en el periodo objeto de recopilación, el TSJ de La Rioja ha enjuiciado dos asuntos relacionados con sanciones en el ámbito de la caza y la pesca, con resultado final dispar.

Por un lado, en la Sentencia núm. 142/2019, de 2 de mayo, el Tribunal estima el recurso presentado por el recurrente y anula la Resolución del Consejero de Agricultura, Ganadería y Medio Ambiente por la que se imponía una sanción de 3.302 euros y sanción accesoria de pérdida de la licencia de caza en vigor e inhabilitación para obtenerla por un periodo de 3 años y 6 meses por la comisión de una infracción muy grave prevista en el art. 81.1 de la Ley 9/1998, de 2 de julio, de Caza de La Rioja y de una infracción grave prevista en el art. 82.13 de la misma Ley.

El Tribunal entiende que la prueba aportada por la Administración para desvirtuar la presunción de inocencia -esto es, la denuncia formulada por el agente de la autoridad y su ratificación posterior- no puede considerarse suficiente cuando se ha negado la práctica de la prueba solicitada por el recurrente, que consistía en la testificación de la esposa del guarda forestal, que se encontraba con él en 
el momento de los hechos denunciados. Esto, según el Tribunal, causa indefensión al expedientado y supone la estimación del recurso.

A distinta conclusión llega el Tribunal en la Sentencia núm. 190/2019, de 11 de junio, en este caso en materia sancionadora de pesca. Por Resolución del Consejero de Agricultura, Ganadería y Medio Ambiente se había impuesto al ahora recurrente la sanción de multa de 3.900 euros, pago de indemnización de daños y perjuicios de 126 euros, decomiso de las redes de pesca y embarcación hinchable, decomiso de los ejemplares ocupados y pérdida de la licencia en vigor e inhabilitación para obtenerla durante 10 años por haber cometido cuatro infracciones tipificadas en la Ley 2/2006, de 28 de febrero, de Pesca de La Rioja por pescar desde embarcación y con redes en lugar no permitido y hacerlo, además, sin licencia de pesca en vigor y sin permiso en un coto.

Entiende el Tribunal en este caso que la comisión de los hechos y la participación del recurrente en los mismos queda acreditada y que no se ha vulnerado ninguno de sus derechos en relación con el procedimiento sancionador, considerando que no tienen credibilidad las alegaciones vertidas por él teniendo en cuenta que en el momento de la intercepción por parte de la Guardia Civil manifestó haber estado pescando sin licencia e incumpliendo las condiciones legales junto con sus acompañantes. 